\title{
OS ÚLTIMOS DEZ ANOS DE GOVERNO EM MINAS GERAIS: A POLÍTICA DE RESULTADOS E O TRABALHO DOCENTE
}

\author{
Maria Helena Augusto*
}

\begin{abstract}
RESUMO: Neste artigo, escrito a partir de pesquisas sobre as políticas de resultados na área educacional, em vigência por mais de dez anos em Minas Gerais (2003 a 2012), propõem-se reflexões sobre as suas consequências no trabalho docente. Essas políticas de resultados são características de um modelo de gestão de controle, que centraliza a eficácia escolar como foco, e instituiu, nos últimos cinco anos, o Prêmio de Produtividade, um bônus salarial anual para os professores que obtêm os resultados definidos pelo sistema de ensino. O que se coloca para reflexão é se tais bônus de premiação não se constituem em uma forma de camuflar/dissimular a degradação das condições de trabalho e os baixos salários dos profissionais da educação pública em Minas Gerais.
\end{abstract}

Palavras-chave: Política de resultados. Prêmio de produtividade. Responsabilização.

\section{The Past ten years of Government in Minas Gerais: THE RESULT POLICY AND THE TEACHING PRACTICE}

\begin{abstract}
This article, based on research that examined educational policies focusing on results - which have been in place for over ten years in Minas Gerais, Brazil (since 2003) -, proposes a reflection upon its consequences in the teaching practice. These result-based policies are characteristic of a control model of management, which focuses on school efficiency and has, over the past five years, instituted the Productivity Award, a bonus added to the yearly wage of teachers, for those who obtain the results defined by the Educational system. What is problematized herein is whether such bonuses are not a means to disguise/dissimulate the degradation of working conditions and the low salaries of public education professionals in Minas Gerais.
\end{abstract}

Key words: Result-based policy. Productivity award. Accountability.

Faculdade de Educação da Universidade Federal de Minas Gerais (UFMG). Belo Horizonte (MG) - Brasil.

Contato com a autora: <malenaoga20@gmail.com> 
Os últimos dez anos de governo em Minas Gerais: a política de resultados e o trabalho docente

\author{
LES DERNIERES DIX ANNÉES DU GOUVERNEMENT DANS \\ L'etat de Minas Gerais: la politique de Résultats et \\ LE TRAVAIL ENSEIGNANT
}

\begin{abstract}
RÉSUMÉ: Cet article qui a été écrit à partir des recherches sur les politiques de résultats dans le secteur scolaire, en vigueur il y a plus de dix ans dans l’Etat de Minas Gerais (de 2003 à 2012), propose des réflexions sur les conséquences dans le travail enseignant. Ces politiques de résultats sont caractéristiques d'un modèle de gestion de contrôle qui centralise l'efficacité scolaire comme cible, et a institué, pendant ces cinq dernières années, le Prix de Productivité, un bonus salarial annuel, pour les enseignants qui obtiennent les résultats définis par le système d'enseignement. Cela pose une réflexion: si tel bonus ne serait pas une forme de camoufler/dissimuler la dégradation des conditions de travail et les bas salaires des professionnels de l'éducation publique dans Minas Gerais.
\end{abstract}

Mots-clés: Politique de résultats. Prix de productivité. Responsabilisation.

\title{
Introdução
}

$\mathrm{N}$

as últimas duas décadas, a avaliação dos sistemas educacionais tem assumido, não só no Brasil como em outros países, grandes proporções, considerando as questões relacionadas à eficácia escolar e à equidade desses sistemas. Essas avaliações, da forma como têm sido concebidas e realizadas, tanto em âmbito nacional como internacional, representam formas de regulação decontrole dos sistemas de ensino e enfatizam, muitas delas, a meritocracia, em uma lógica empresarial que coloca sobre as escolas e professores a responsabilização pelo desempenho dos alunos.

Segundo Freitas (2011), trata-se de uma forma deresponsabilização e/ou meritocracia, em um contexto neotecnicista, quando a racionalidade técnica assume a forma de "standards" de aprendizagem, medidos em testes padronizados, com ênfase nos processos de gerenciamento da força detrabalho da escola (controle pelo processo, bônus e punições), ancorados nas mesmas concepçõesoriundas da psicologia behaviorista, da econometria e das ciências da informação.

No Brasil, o Índice de Desenvolvimento da Educação Básica (Ideb) - criado em 2007 pelo Instituto Nacional de Estudos e Pesquisas Educacionais Anísio Teixeira (Inep) - é, segundo o MEC, o condutor da política pública em prol da qualidade da educação. Constitui-se ferramenta para acompanhamento das metas de qualidade do Plano de Desenvolvimento para a Educação (PDE), prevendo para 2022 a média 6, que apontaria um sistema educacional de qualidade, comparável ao dos países desenvolvidos. No mesmo sentido, o Plano Nacional de Educação (PNE) para os próximos dez anos estabelece na Meta 7 que o país devefomentar a qualidade da 
educação básica em todas as etapas e modalidades, prevendo melhoria do fluxo escolar e da aprendizagem, de modo a atingir as médias nacionais para o Ideb.

Alguns estados também estabelecem sistemas de avaliaçãoda educação básica em suas redes públicas, que preveem bonificações salariais, como é o caso de São Paulo com o Sistema de Avaliação do Rendimento Escolar do Estado de São Paulo (Saresp), Pernambuco, com o Sistema de Avaliação Educacional de Pernambuco (Saepe), e Minas Gerais, com o Sistema Mineiro de Avaliação da Educação Básica (Simave). ${ }^{1}$

Neste texto, escrito a partir de pesquisas que vêm sendo desenvolvidas no âmbito da Rede Estadual de Ensino de Minas Gerais (REE-MG), são analisadas as políticas de governo nos últimos dez anos e seus efeitos sobre o trabalho docente. Tais políticas de resultados, em vigência desde 2003, caracterizam-se pela adoção, nos últimos cinco anos, de um bônus salarial associado ao desempenho dos professores, denominado Prêmio de Produtividade, em análise neste artigo. O que se interroga é se tais bônus e outras estratégias de premiação por mérito não se constituem uma forma de camuflar/dissimular a degradação das condições de trabalho: os baixos salários dos profissionais da educação pública na REE-MG - que são oriundos de uma política remuneratória, retrato da significativa (des)valorização dos professores ao longo dos últimos dez anos.

Como o fazem Sousa e Lopes (2010), quando questionam as avaliações externas em educação, pergunta-se sobre a qualidade desta educação, na proposta de governo na REE-MG. Segundo as autoras, a defesa da qualidade é bandeira comum, mas o que se constata nos exames em larga escala é que o desempenho do estudante é medido apenas em Língua Portuguesa e Matemática. Como avaliar a qualidade da educação tendo por base os conhecimentos de apenas duas áreas do currículo? A qualidade educacional é mais abrangente, segundo Sousa (2003). Os enfoques e os critérios, assumidos em um processo de avaliação, revelam as opções axiológicas daqueles que o concebem, segundo a autora. Assim, o pressuposto é que a qualidade, subjacente a tais exames de avaliação externa, revele um viés tecnicista, com ênfase nos produtos e resultados. A ênfase da qualidade da educação, segundo Sousa (op. cit.), deve-se deslocar dos produtos para os processos da prática pedagógica. Considerando o aspecto sociopolítico da educação, a avaliação deveria proporcionar o avanço da prática pedagógica, tendo em vista a emancipação social. Para tanto, seria importante, como diz Freitas (2007), citando Bondioli (2004), criar parceria entre escola e governo local, por meio de um processo chamado qualidade negociada, pela via da avaliação institucional. Isto significa explicitar descritores da qualidade a serem negociados, em um processo participativo, autorreflexivo, contextual/plural, processual e transformador, afirma o autor.

A questão em debate neste texto refere-se, pois, aos usos que o Governo do Estado de Minas Gerais faz dos resultados das avaliações. Poderiam servir para apontar 
os caminhos a seguir, em busca da efetividade do direito à educação de qualidade social para todos, e que, pela Constituição Federal de 1988 e emendas posteriores, compete ao Estado garantir. Entretanto, tem servido para instrumentalizar a ação política, na promoção de mecanismos de premiação de desempenhos, considerados exitosos, sanções e punições, em caso de fracassos.

As políticas educacionais ficam, em tal situação, subordinadas à lógica econômica, pois o que está em jogo é a eficácia dos resultados quantitativos, tendo como pressuposto a eficiência, segundo as palavras do próprio governador Aécio Neves, em seu primeiro mandato:"Gastar menos e ter melhores resultados".

Em muitos contextos, os usos que se faz da avaliação assumem o significado de uma "obrigação de resultados" (DEMAILLY, 2001, 2004; LESSARD, 2004, 2009; MAROY, 2008). A obrigação de resultados é compreendida como a responsabilização das escolas e dos professores pelos resultados escolares. E a situação ocorre tanto devido a uma alta exigência social de melhores resultados por parte das escolas, motivada por uma crítica de ineficiência dos serviços educativos, como por influência/exigência das organizações internacionais sobre os sistemas educacionais, direcionando as políticas públicas, em contexto mundial. Os autores questionam a cobrança de resultados associada a prêmios e punições, considerando a existência de outros fatores que interferem no processo de aprendizagem e a diversidade de contextos socioeconômicos em que as escolas estão inseridas. É o que vem ocorrendo em Minas Gerais, com o programa de governo denominado "Estado para Resultados": política esta que a pesquisa em questão tem buscado compreender, por meio de estudo e análise documental, entrevistas com professores e gestores do sistema e observação in loco, em escolas da REE-MG, no município de Belo Horizonte.

\section{A política de resultados em Minas Gerais: uma análise crítica}

O governo do estado de Minas Gerais, gestão Aécio Neves (período 2003 a 2010), afirmando ter encontrado grave crise fiscal e administrativa, herdada da gestão anterior, Itamar Franco (1998 a 2002), propôs um programa de governo denominado "Choque de Gestão", constituído por ações de racionalização de processos e modernização de sistemas, reestruturação do aparelho do Estado, avaliação de desempenho institucional e individual, com o objetivo, conforme declarado, de melhorar a qualidade e reduzir os custos dos serviços públicos. Esse programa, cujo mentor é Antônio Anastasia, teve continuidade no período subsequente (2011-2014), quando Anastasia foi eleito governador, em substituição a Neves. Em seu segundo ciclo de reformas, a partir de 2008, o programa é denominado "Estado para Resultados"(GUIMARÃES; PORDEUS; CAMPOS, 2010). 
O "Choque de Gestão" foi considerado, segundo Vilhena et al. (2006), "não uma simples reforma administrativa, mas um programa que apresenta uma singularidade", sendo denominado pela autora como "reforma de segunda geração", estabelecido de acordo com as seguintes diretrizes: a) de um estado provedor para um estado regulador e promotor; $b$ ) da burocracia como forma de gestão para o enfoque gerencial; c) de uma forma de controle sobre procedimentos para uma forma de controle sobre resultados, tendo por base o comprometimento e alinhamento dos gestores.

O "alinhamento das instituições e dos profissionais" aos objetivos e às prioridades do programa “Choque de Gestão" e, posteriormente, ao "Estado para Resultados" deve ser obtido, segundo os pressupostos do governo, por meio de um "Acordo de Resultados", um instrumento gerencial, a partir de um pacto de resultados para o alcance dos objetivos e metas do programa, expressos em sua agenda. ${ }^{2} \mathrm{O}$ "Acordo de Resultados", vigente no estado, é um contrato de gestão, definido pelo governo estadual, no sentido de obter mais eficácia e eficiência nos serviços públicos. A lei que disciplina esse Acordo é a de n. 17.600, de julho de 2008. Em Minas Gerais, foi previsto em duas etapas: a primeira compreende o compromisso das Secretarias de Estado com o governador; a segunda, o compromisso das Secretarias de Estado com os seus órgãos componentes. No caso da educação, os órgãos intermediários do sistema são as Superintendências Regionais de Ensino (SER) e os órgãos finais, onde se processa o trabalho educativo, são as escolas públicas estaduais. Portanto, todas as escolas se veem na obrigação de assinar o "Acordo de Resultados", no qual assumem o compromisso de obter os índices de desempenho, estipulados pelo órgão central, no Sistema Mineiro de Avaliação da Educação Básica(Simave).

A legislação, que estabeleceu a política de resultados em Minas Gerais, também estabeleceu um bônus salarial, chamado "Prêmio de Produtividade". A Lei n. 17.600/2008 assim o define:

Art. 23. O Prêmio por Produtividade é um bônus a ser pago aos servidores em efetivo exercício em órgão ou entidade que:

I - seja signatário de Acordo de Resultados com previsão expressa de pagamento de Prêmio por Produtividade;

II - obtenha resultado satisfatório na Avaliação de Desempenho Institucional, a que se refere $\mathrm{o}$ inciso IV do art. 11, realizada no período de referência, nos termos definidos em decreto; e

III - realize a Avaliação de Desempenho Individual permanente de seus servidores, nos termos da legislação vigente.

O valor do Prêmio é proporcional à nota obtida na avaliação de desempenho institucional e individual e aos dias efetivamente trabalhados, no período a que se refere o benefício, não sendo incorporado à remuneração e nem aos proventos de 
aposentadoria. Os professores contratados temporáriosnão têm direito ao prêmio, mesmo exercendo as mesmas funções e tendo as mesmas responsabilidades dos efetivos. Ele foi instituído com a intenção de se constituir em um mecanismo de adesão dos profissionais às medidas reguladoras de resultados.

O que o governo pretendeu ao instituir a avaliação de desempenho por mérito, a partir de 2003, foi procurar transformar as relações de trabalho, definindo a produtividade como o diferencial, ao avaliar os professores. A obrigação de resultados, no caso dos professores em Minas Gerais, não se fundamentou no consentimento dos mesmos, uma vez que eles - os professores - não participaram do processo de implementação da política de resultados. Não se pode dizer, portanto, que seja uma medida justa, considerando as diferenças entre comunidades atendidas e espaços de localização das escolas, formação e experiência de trabalho dos docentes, nível socioeconômico dos alunos. O ponto de partida da corrida pelos resultados não é o mesmo para todos: escolas, professores e alunos. Os professores são constrangidos a obter os resultados estipulados, pois caso não o façam as suas escolas não alcançam os percentuais definidos. A progressão na carreira docente e a premiação são vinculadas à obtenção dos resultados dos alunos no Simave.

Em Minas Gerais, o governo afixou na portaria das escolas,em locais de fácil acesso e visibilidade, placas com os resultados do Ideb. Assim, segundo o portal da Secretaria de Educação, pais, alunos e professores se tornam parceiros no desafio de melhorar o desempenho escolar. O governo divulga também na mídia os resultados educacionais, ressaltando a boa colocação no Ideb, nos anos iniciais do ensino fundamental. Além disso, a política de resultados de Minas Gerais é bem vista pelo Banco Mundial, que considera a medida de bônus de produtividade adotada como uma estratégia para melhorar a qualidade da educação. Segundo o relatório do Banco Mundial denominado Achieving World-Class Education in Brazil: the next agend, publicado em novembro de 2011, o estado de Minas Gerais tem sido líder no SchoolBased Management, com as políticas que incentivam o desenvolvimento da gestão educacional, sendo uma delas a premiação pelo mérito.

Entretanto, o estado se exime da responsabilidade de providenciar os meios necessários às adequadas condições de trabalho docente, como salários, carreiras atraentes e infraestrutura escolar. A responsabilização das escolas e dos professores, pela vinculação entre os resultados do Simave e as avaliações das escolas e professores, é um arranjo do estado, no sentido de isentar-se das suas obrigações, em relação ao direito aos serviços de educação de qualidade social para todos. Constitui-se um paradoxo: o programa de governo estabelece estratégias gerenciais e a premiação pelo mérito, mas não reconhece e nem valoriza os professores. Entretanto, espera que estejam "alinhados" às políticas de resultados. 


\section{A premiação pelo mérito na área pública: origem, contexto e pers- pectivas}

Para melhor compreensão de como se desenvolvem as estratégias de premiação por mérito na administração pública, torna-se importante verificar como tais medidas ocorrem nas empresas privadas, de onde se originam. Segundo estudo realizado por Oyadomari e Coelho (2009), foi possível constatar o emprego de um Sistema de Controle Gerencial (SCG), em 21 empresas de negócios, situadas entre as maiores do Brasil. A partir dos estudos, os autores concluem que o SCG é uma medida utilizada pela alta administração para controlar as atividades da organização, o comportamento e as decisões dos empregados e para observar se estas açõessão executadas de acordo com as estratégias organizacionais. O Sistema abrange as formas que os gerentes usam para assegurar que o comportamento e as decisões dos subordinados sejam consistentes com os objetivos e estratégias organizacionais. Entretanto, o grau de execução desses objetivos e estratégias organizacionais depende do envolvimento das pessoas, já que estas são as responsáveis pela execução dos objetivos planejados, e motivá-las não é uma tarefa fácil, pois pode haver conflito entre interesses pessoais e organizacionais (OYADOMARI; COELHO, 2009).

Segundo os autores, alguns aspectos devem ser considerados como pontos fundamentais de um SCG. Os indivíduos, geralmente, agem em prol de seus interesses pessoais; sendo assim, o Sistema deve ser desenhado de forma a obter vantagens, tendo em vista este comportamento humano; os indivíduos devem ser alinhados aos objetivos da organização, contemplando incentivos que promovam a congruência de metas e que os estimulem a buscá-las. O papel e o desafio da gerência são assegurar que os objetivos das pessoas estejam sintonizados aos objetivos da empresa. As formas de premiação constituem, segundo os autores, um mecanismo empregado pela gerência com tal propósito.

Entre os autores que escrevem sobre o tema, e ainda movimentos e organizações ligados à educação, alguns desenvolvem argumentos ora favoráveis ao pagamento de incentivos por mérito e outros expressam posições críticas sobre o assunto, revelando postura desfavorável. Segundo os favoráveis, os incentivos ou premiações se constituem uma forma de distinguir os "bons" e os "maus" professores, e levariam aqueles interessados em se dedicar mais ao seu trabalho a se esforçarem para elevar o desempenho dos alunos. Para eles é incompreensível que um professor acomodado e medíocre tenha o mesmo salário de outro, que se empenha e seja dedicado à profissão. A visão dos autores, que defendem a meritocracia, revela ênfase na educação como condição para o desenvolvimento econômico e para inserção do país no grupo dos países desenvolvidos (SOUSA, 2003). Eles apontam, como saída para a solução do mau desempenho da educação, a associação entre o desempenho 
Os últimos dez anos de governo em Minas Gerais: a política de resultados e o trabalho docente

dos alunos nos exames externos e o pagamento do professor, enquadrando-se aí o pagamento dos prêmios. Esses autores se baseiam, ao formular argumentos favoráveis ao pagamento discricionário (por mérito), no fato de que a forma tradicional de remuneração não produz incentivo e não estimula o professor a melhorar o seu desempenho.

Dentre esses autores, destaca-se Morduchowicz (2003), segundo o qual a justificativa do pagamento por mérito reside, em última instância, no seguinte raciocínio: se os professores forem remunerados competitivamente em função de seus respectivos desempenhos, trabalharão mais, e os mais eficazes serão recompensados monetariamente. Diante dos problemas da educação, segundo o autor, a questão central a resolver é descobrir a forma de garantir que os prestadores diretos do serviço - professores, por exemplo - possam agir de acordo com os interesses da organização. As duas maneiras principais de consegui-lo são: (a) vincular seus pagamentos ao resultado da sua ação e/ ou (b) destinar maior quantidade de recursos ao monitoramento dessa ação. Esta segunda questão implicaria maior intervenção estatal - justamente o que se questiona, segundo o autor. Este é o motivo pelo qual a maior parte das análises e propostas se dedica à questão da vinculação entre salários e resultados.

O sistema de remuneração diferenciada, com o pagamento de bônus salariais aos que se destacam, é proposto pelos seus defensores como uma saída para melhorar os desempenhos dos sistemas educacionais. A qualidade da educação estaria, segundo tal ponto de vista, garantida, uma vez que o pressuposto é: se os professores recebem mais, produzem mais, e assim os alunos aprendem mais.

Segundo o Documento n. 43 da série Seminários e Conferências, intitulado "Investir melhor para investir más. Financiamento y gestión de la educación en América Latina y Caribe", da Comissión Econômica para América Latina y el Caribe (Cepal) y Organización de las Naciones Unidas para la Educación, la Ciência y la Cultura (Unesco), o sistema de prestação de contas das escolas introduz rotinas de compromisso e monitoramento que impõem maior sentido de responsabilidade pelo funcionamento e pelos resultados. O Documento apregoa os méritos, incentiva a utilização da prestação de contas pelas escolas aos pais e às comunidades, e deixa claro que o compromisso com a prestação de contas requer incentivos: "É importante ligar as prestações de contas aos sistemas meritocráticos de prêmios e sanções ao pessoal docente e aos diretores das escolas. Incentivos e prestação de contas são as duas caras da mesma moeda. Desta forma, os professores não têm como resistir às medidas de prestação de contas" (CEPAL/UNESCO, 2003, p. 82).

Nesse Documento, estão muito nítidas as propostas de se promover a obrigação de resultados como modo de regulação de controle das políticas públicas. 
O Documento apresenta a proposta como um desafio e incentiva os governos a assim fazê-lo.

Alguns autores no Brasil, a partir de pesquisas e estudos sobre as políticas de educação, têm feito a crítica da responsabilização, da premiação e sanção aos professores. Segundo Freitas (2011), a meritocracia é o ingrediente básico do processo de responsabilização, pelo qual se pretende legitimar, perante a opinião pública, as ações de controle dos profissionais da educação, a forma de gestão e a própria privatização das escolas. A responsabilização legitima vários interesses sob o manto da objetividade científica das avaliações. De acordo com o autor (2012), estudos têm apresentado resultados negativos ou nulos, bem como efeitos colaterais de diversas naturezas, podendo ser mencionados, entre outros, o estreitamento curricular, a competição entre escolas, entre os profissionais da educação, as fraudes, o "ensinar para os testes", a destruição moral do professor. Tudo isso vem provocando a destruição do sistema público de ensino. $\mathrm{O}$ autor demonstra em seus textos que os efeitos dessa política de meritocracia sobre a melhoria da educação são inexistentes. Afonso (2009) faz a crítica à accountability, baseada em testes estandardizados e rankings escolares. Considera, citando Ranson (2003), que, se o modelo de accountability for associado a uma imagem punitiva, pode ser considerado como um "anátema para a comunidade dos profissionais". A prestação de contas, para salvaguardar direitos fundamentais, precisa prever procedimentos democráticos, garantir o direito à informação e à transparência (AFONSO, op. cit.).

Lessard (2009) aponta a contradição na cobrança de resultados, pois são sempre as mesmas escolas que obtêm os melhores desempenhos. De um ano para o outro, as posições dessas escolas se reforçam nas classificações por resultados. $\mathrm{O}$ fato pode ser explicado pela seguinte razão: tais escolas têm um poder maior de atração de professores com melhor formação e maior experiência de trabalho, mais habilitados, e de alunos cujas famílias demonstrem maior empenho na escolarização dos seus filhos. $\mathrm{O}$ autor considera que, de modo geral, as escolas de periferia, que recebem os alunos com mais dificuldade de aprendizagem e professores novatos e menos experientes, muitas vezes não habilitados, ficam em um círculo vicioso e não conseguem obter os resultados definidos. Cria-se, desta forma, uma situação injusta, em que pesam outros fatores não considerados no contexto de cobrança de resultados.

Segundo Demailly (2001), não pode ser considerada justa uma escola em que os resultados são expressos exclusivamente em termos de índices e de pontuações, obtidos em exames realizados fora do contexto escolar, e quando são ignorados valores, ética, formação e cidadania. Passa-se, desta forma, de uma legitimidade substancial (princípios e fins educacionais) para uma legitimidade procedimental, em que a "cultura da avaliação", tendo por base um plano 
ideológico-prático, é considerada como uma "maleta de ferramentas" que será utilizada pelo sistema educacional. Além disso, os professores não participam da formulação de tais medidas de avaliação, associadas à responsabilização. Para Demailly (2004), o limite da obrigação de resultados é o da possibilidade de formulação democrática de uma vontade geral. Ao analisar a questão das penalidades impostas aos professores, diz a autora:

Em nome de que sancionar os professores, se os resultados a esperar não são colocados por uma vontade geral legítima, que foi formulada por meios legítimos e que têm um conteúdo legítimo. Como educador, minha responsabilidade para até a responsabilidade do outro. Eu posso ser responsável pelo outro, mas não em seu lugar. Eu tenho sempre uma parte da responsabilidade em toda circunstância educativa, mas somente uma parte. (DEMAILLY, op. cit., p. 111)

\section{A política de resultados e a avaliação dos professores}

Segundo Duran (1999), a análise das políticas, ao olhar do cientista social, se interessa não só pelo que a autoridade constituída faz, mas também pelo que ela se renuncia a fazer, diante de uma situação ou problema. Não pode se ater somente ao texto da lei, às falas dos governantes, mas ir além deles. Faz-se necessário um olhar agnóstico do cientista social. É esta a perspectiva de análise das políticas de governo, nas pesquisas que deram origem a este artigo.

Na política de resultados em Minas Gerais, o bônus salarial, denominado "Prêmio de Produtividade", é condicionado à melhoria dos resultados escolares do Simave. O sistema de avaliação institucional por equipe escolar, segundo a Lei n. $17.600 / 2008$, exige pontuação igual ou superior a 70\% (setenta por cento) do total estipulado, para se alcançar o direito à premiação. Como condições para receber este Prêmio, o docente deve ter cargo de provimento efetivo e ter também obtido, na Avaliação de Desempenho Individual, resultado igual ou superior a 70\% (setenta por cento).

Em caso de não se atingir as metas, previstas por escola, os profissionais da educação perdem o direito ao benefício ${ }^{3}$ e o diretor perde também as prerrogativas da autonomia, concedidas em função do Acordo, e em muitas situações perde também o seu cargo de direção.

Os professores se veem limitados em sua autonomia profissional, uma vez que os conteúdos das aulas, bem como a sua atuação didática, são previamente definidos, em função dos requisitos dos exames do Simave, o que pôde ser observado nas escolas pesquisadas. Eles foram interrogados sobre a vinculação da sua avaliação de desempenho aos resultados dos alunos no Simave e 86\% (dos 54 
entrevistados) se posicionaram contrários à vinculação, citando outros fatores que interferem no processo de aprendizagem dos alunos.

Em Minas Gerais, os salários dos professores estão defasados mesmo em relação a outros sistemas públicos de ensino de outros estados. Um professor efetivo, com licenciatura plena, tendo dez anos de trabalho na REE-MG, recebe, segundo a tabela constante da Lei n. 19.837/2011, um valor de $\mathrm{R} \$ 1.183,87$ (um mil cento e oitenta e três reais e oitenta e sete centavos), para uma jornada de 24 horas semanais de trabalho. O Plano de Carreira dos Profissionais da Educação, expresso nas Leis n. 15.293/2004, 15.788/2005 e alterações posteriores, não tem atendido aos interesses desses profissionais. Em relação aos salários e ao Plano de Carreira, observa-se um elevado grau de insatisfação entre os docentes, que se sentem desvalorizados pelo sistema. Em resposta a uma das questões da pesquisa, levantamento realizado no primeiro semestre de 2012 apontou, das respostas válidas, que 98\% dos professores estão insatisfeitos com a sua remuneração pela Lei n. 19.837/2011 - Lei do Subsídio. Os docentes declaram insatisfação, em relação: a) ao não cumprimento, pelo governo do Estado, da Lei n. 11.738/2008 - do Piso Salarial Profissional Nacional para os Profissionais do Magistério Público da Educação Básica; e b) à fixação pelo governo do Estado de uma forma de remuneração para as carreiras da educação básica, denominada subsídio, em vigência a partir de janeiro de 2012.

O subsídio é uma forma de pagamento que incorpora todos os benefícios e o salário em uma única parcela. Em Minas Gerais o subsídio foi instituído pela Lei n. 18.975/2010, tendo sido estabelecido um prazo de noventa dias para a opção pelo retorno à forma de pagamento anterior (vencimentos mais gratificações). Este prazo foi sendo prorrogado até setembro de 2011 e foi muito elevado o número de optantes ao retorno, uma vez que, no entendimento dos profissionais do magistério, se tratava de uma forma de omissão, por parte do governo, do cumprimento da lei do Piso. Essas medidas levaram os profissionais da educação a um movimento de resistência aberta, uma greve de paralisação das atividades docentes, no ano letivo de 2011, que durou 112 dias e teve repercussão em âmbito nacional. A paralisação foi encerrada, em setembro de 2011, mediante um acordo do governo com os representantes do movimento, com revisão da política de subsídio e constituição de uma comissão de negociação.

O governo de Minas Gerais, com o aval da Assembleia Legislativa, onde tem maioria, em 2 de dezembro de 2011, conseguiu aprovar, apesar do desacordo dos profissionais da educação, uma nova Lei: a n. 19.837/2011, que manteve o subsídio, como política remuneratória, e alterações na carreira dos profissionais da educação, aumentando o intervalo de tempo nas promoções e reduzindo os percentuais anteriormente previstos, além de congelar as carreiras até janeiro de 2015. 
Segundo a afirmação de Duran (1999), faz-se necessário, na análise das políticas públicas, interrogar sobre a renúncia do governo em cumprir determinadas ações que dele são esperadas. É o que está sendo proposto para reflexão neste artigo: o que levaria o governo de Minas Gerais a pagar um bônus salarial, reduzir direitos e não desistir da política remuneratória pelo subsídio? O Sindicato Único dos Trabalhadores da Educação de Minas Gerais (Sind-UTE) declarou que a aprovação (em lei) da prorrogação do subsídio foi uma medida contrária aos interesses da carreira, uma forma de ignorar o negociado entre as partes, que definiu o fim da greve. $\mathrm{O}$ governo afirmou na mídia e em suas declarações, publicadas em seu portal, não somente cumprir, mas remunerar os profissionais da educação acima do piso salarial. Por outro lado, o Sindicato informa, conforme publicado em seu portal, que o governo descumpriu o acordo assinado e que também não cumpre a Lei do Piso Salarial, com o pagamento do subsídio, vigente a partir de 2012. As decisões do governo foram centralizadas nos gestores do sistema e as negociações foram interrompidas.

Nesta pesquisa, foi solicitado aos sujeitos da entrevista de três escolas públicas que, mediante uma situação proposta, comparassem os seus salários atuais pelo subsídio ao que está previsto na Lei n. 11.738/ 2008 (na hipótese de estarem recebendo segundo essa Lei). Dos 54 professores entrevistados, 43 consideraram que recebem na atualidade, pelo subsídio, menos do que receberiam pela Lei do Piso, e 7 (sete) não responderam, conforme exposto no quadro a seguir:

\section{Quadro 1}

Avaliação do salário atual pelos docentes, em relação à Lei n. 11.738/2008

\begin{tabular}{|l|c|c|c|c|}
\hline $\begin{array}{l}\text { Comparando o subsídio que você recebe (atual) } \\
\text { ao vencimento definido pela Lei n. 11. 738/2008, } \\
\text { considerando as atualizações de valores, a partir } \\
\text { de janeiro de 2009, conforme decisão do Supre- } \\
\text { mo Tribunal Federal, ele seria: }\end{array}$ & Escola A & Escola B & Escola C & TOTAL \\
\hline Maior & - & - & 4 & 4 \\
Menor & 18 & 4 & 21 & 43 \\
Igual & - & - & - & - \\
Não respondeu & 4 & 2 & 1 & 7 \\
Total das respostas & 22 & 6 & 26 & 54 \\
\hline
\end{tabular}

Fonte: banco de dados da pesquisa.

No momento atual, o que se observa no ambiente escolar é um movimento de resignação, de conformação às situações de controle vertical e hierárquico. As 
carreiras estão congeladas pela referida Lei e a estrutura de organização escolar não permite um trabalho compartilhado com os colegas, não permite disponibilidade de tempo para dar aos alunos a atenção necessária, nem para pensar e refletir sobre o trabalho que os docentes realizam. Conforme relata um professor dos anos finais do ensino fundamental de uma escola da rede pública estadual de Minas Gerais, entrevistado em 18 de maio de 2012:

O governo incorporou todos os benefícios e gratificações em um único valor, chamado de subsídio, e congelou os atuais salários até o ano de 2015. A gente não tem mais Plano de Carreira, pois está tudo paralisado no Estado, até 2015. Hoje é subsídio, e o governo paga como teto o que deveria pagar como base. A gente recebe um subsídio vergonhoso, mesmo com licenciatura plena, e é o mesmo valor de quem ingressa agora no Estado. Muito estranha essa carreira! E o pior é que tem que levar trabalho para fazer em casa, não tem tempo na escola para tudo o que precisa!!!

A carga horária semanal de trabalho do professor de educação básica - dos últimos anos de ensino fundamental e do ensino médio - corresponde, no momento atual, a uma jornada de trabalho de 24 horas semanais que compreende um terço para atividades extraclasse (oito horas), sendo as outras 16 horas restantes para atividades da docência, em diversas turmas de anos de escolaridade diferenciados e um elevado número de alunos, em distintos graus de aprendizagem. Os professores trabalham em mais de um turno na mesma escola ou em escolas diferentes, como meio de ampliar os seus salários.

Tendo por base os estudos de Bruno (2011), pode-se concluir que o enfoque dos sistemas nacionais de educação foi, ao longo do século $X X$, reorganizado, tendo como referência os modelos de gestão e administração empresarial. Os professores e outros trabalhadores da educação passam a ter o seu trabalho regido pela "lei do valor", que visa manter baixa a remuneração dessa força de trabalho. Segundo a autora (2011), a autoridade profissional dos professores está bem fragilizada pelas novas formas de gestão que lhes retiram a autonomia, subordinando-os a diretrizes centrais. A situação de fragmentação da categoria, aliada às políticas de gratificação por desempenho, baseadas em critérios discutíveis de eficiência e produtividade, e a dispersão da jornada de trabalho por mais de uma instituição escolar se constituem em obstáculos que os levam a uma situação de indiferença, de apatia, e a formas de resistência individual no ambiente de trabalho, que em nada alteram o quadro das suas dificuldades.

\section{Considerações finais}

Em Minas Gerais, a política de resultados é vista pelos dirigentes da Secretaria de Estado da Educação (SEE-MG) como um instrumento do seu poder de cobrança, 
pois ela é vinculada aos componentes de meios de subsistência dos professores, ou seja, seus reajustes salariais, promoções e progressões na carreira e prêmios pelo desempenho. Pode também ser bem vista pelo público externo, devido às propagandas do governo, e por aqueles que não conhecem o cotidiano de trabalho e os desafios de trabalhar nas escolas estaduais em condições precárias, que consistem nos baixos salários, mesmo comparando-os aos de outros estados da Federação, e na infraestrutura inadequada. São situações que têm sido observadas no trabalho de campo em Minas Gerais, tais como salas de aula superlotadas, inexistência de espaços e tempos apropriados para o trabalho coletivo, falta de material didático, de laboratórios, entre outros aspectos como, por exemplo, professores lecionando conteúdos para os quais não são habilitados, em função da exigência curricular e mesmo das contratações temporárias, que retratam a desvalorização profissional. A política de resultados, como vem sendo feita em Minas Gerias, é um modelo que coloca sobre os ombros das escolas e professores a responsabilidade pelo sucesso ou o fracasso dos alunos, como se o desempenho acadêmico do aluno dependesse exclusivamente da ação pedagógica do professor, que deve, segundo tal lógica, monitorar resultados, contribuir na economia de despesas, sempre em sintonia com os objetivos mais amplos do governo. Derouet e Derouet-Besson (2009) posicionam a obrigação de resultados para os professores em um quadro de gestão neoliberal da educação. Os autores consideram que um projeto educacional, para contribuir na coesão social, implica o êxito de todos e não apenas de parte das escolas.

Segundo Oliveira (2009), a despeito das variadas críticas ao sistema meritocrático, ele permanece na base dos sistemas escolares nacionais e constantemente é legitimado como critério objetivo na seleção das posições sociais. Tal fato pode ser explicado pela disputa que ocorre em torno do aval dos organismos internacionais de financiamento e das premissas constantes dos seus relatórios sobre a produtividade dos sistemas escolares.

Nestas considerações, reafirmam-se alguns argumentos importantes em relação à questão que foi proposta para reflexão neste artigo:

a) a ilegitimidade da política de resultados, uma vez que não é ancorada na participação do professores, que não a aprovam;

b) o estado de Minas Gerais não cumpre, até o momento, as determinações legais previstas na Lei n. 11.738/2008 e modificações posteriores, bem como as medidas contidas na legislação que regulamenta os Planos de Carreira (Resolução CNE/MEC n. 2/2009 e Parecer CEB/MEC n. 9/2012), mas divulga seu programa de educação e declara que valoriza os professores;

c) a sobreposição da eficiência e da racionalidade econômica em relação ao pagamento de salários dignos aos docentes na REE-MG. O governo ignora a 
insatisfação dos professores com os baixos salários. Na verdade, a decisão em instituir a produtividade representa um engodo junto à comunidade em geral;

d) a premiação pelo mérito, como já foi dito, revela-se uma estratégia com uma lógica questionável, do ponto de vista da justiça social, de adesão à política de resultados do governo atual.

Em Minas, o governo, por meio das medidas previstas, exerce as ações de coordenação, controle e influência e propõe intervenções para introduzir os constrangimentos no sistema educacional. Fica muito evidente, na pesquisa realizada, a contradição entre a realidade de muitas escolas e a pretensão do sistema, sobre os índices a alcançar. O que vem ocorrendo é que as políticas de governo atuais estão distanciadas das políticas de Estado. A questão permanece em aberto, em relação ao seu significado, e é colocada para provocar reflexões. Ela não se esgota neste texto, cuja finalidade é ensejar novos estudos e pesquisas.

\section{Notas}

1. Para mais descrições dos sistemas mencionados, consultar Bonamino e Sousa (2012).

2. O Acordo de Resultados da área educacional está disponível para consulta no sítio eletrônico da Secretaria de Estado da Educação: <www.educacao.mg.gov.br>, acesso em: 12 jul. 2013.

3. A primeira avaliação institucional com base no Acordo de Resultados ocorreu em outubro de 2009. Em estudo realizado em três superintendências da capital, Metropolitana A, B e C, em um total de 420 escolas estaduais de 36 municípios da grande BH, que integram as três SRE, 73,2\% das escolas alcançaram a pontuação acima de $70 \%$.

\section{Referências}

AFONSO, A.J. Nem tudo o que conta em educação é mensurável e comparável. Crítica à accountability baseada em testes estandardizados e rankings escolares. Revista Lusófona de Educação, Lisboa, v. 13, n. 2, 2009.

BONAMINO, A.; SOUSA, S.Z.L. Três gerações de avaliação da educação básica no Brasil: interfaces com o currículo da/na escola. Educação \& Pesquisa, São Paulo, v. 38, n. 2, p. 373-388, abr./jun. 2012.

BONDIOLI, A. O projeto pedagógico da creche e sua avaliação: a qualidade negociada. Campinas: Autores Associados, 2004.

BRASIL. Lei n. 11.738, de 16 de julho de 2008. Regulamenta a alínea "e" do inciso III do Caput do art. 60 do ADCT e institui o piso salarial profissional nacional para os profissionais do magistério público da educação básica. Diário Oficial da União, Brasília, DF, 17 jul. 2008. 
Os últimos dez anos de governo em Minas Gerais: a política de resultados e o trabalho docente

BRUNO, L. Educação e desenvolvimento econômico no Brasil. Revista Brasileira de Educação, Rio de Janeiro, v. 16, n. 48, set.-dez. 2011.

CEPAL/UNESCO. Investir mejor para investir más. Financiamiento y gestión de la educación en América Latina y Caribe. Santiago, Chile: Cepal/Unesco, 2003. (Documento n. 43).

DEMAILLY, L. Enjeux de l'évaluation et régulation des systèmes scolaires. In: DEMAILLY, L. (Éd.).Évalur les polítiqueséducatives. Bruxelles: De Boeck Université, 2001.

DEMAILLY, L. Enjeux et Limites de l'obligation de résultats: quelques réflexions à partir de la politique d'éducation prioritaire en France. In: LESSARD, C.; MEIRIEU, P. (Dir.). L'obligation de résultats en éducation. Laval: Les Presses de l'Université Laval, 2004. p. 105-122.

DEROUET, J.L.; DEROUET-BESSON, M.C. Repenser la justice dans le domaine de l1éducation et de la formation. Berne: Peter Lang; Editions Scientifiques Internationales, 2009.

DURAN, P. Penser l'action publique.Paris: LGDJ,1999. (Colletion Droit et Sociéte).

FREITAS, L.C. A eliminação adiada: o ocaso das classes populares no interior da escola e a ocultação da (má) qualidade do ensino. Educação \& Sociedade, Campinas, v. 28, n. 100, p. 965-987, 2007.

FREITAS, L.C. Responsabilização, meritocracia e privatização. Conseguiremos escapar ao tecnicismo? In: SEMINÁRIO DE EDUCAÇÃO BRASILEIRA, 3., Simpósio "PNE: diretrizes para avaliação e regulação da educação nacional", Centro de Estudos Educação e Sociedade (Cedes), Campinas, fev. 2011.

FREITAS, L.C. Os reformadores empresariais da educação: da desmoralização do magistério à destruição do sistema público de educação. Educação E Sociedade, Campinas, v. 33, n. 119, p. 379-404, 2012.

GUIMARÃES, T.B.;PORDEUS, I.A.; CAMPOS,E.S.A. (Org.). Estado para resultados. Avanços no monitoramento e avaliação da gestão pública em Minas Gerais. BeloHorizonte: Editora da UFMG, 2010.

LESSARD, C. L'obligation de résultats en éducation: de quoi s'agit-il? Le contexte québecois d'une demande sociale, une rhétorique du changement et une extension de la recherche. In: LESSARD, C.; MEIREU, P. L'obligation de résultats en éducation. Laval: Les Presses de l’Université Laval, 2004.

LESSARD, C. Les hauts et les bas de l'obligation de résultats en éducation.In: La performance, sa mesure. Enjeux éthiques. Revue Administration et Éducation, Paris, p. 17-26, 2009. 
MAROY, C. Régulation des systèmes educatifs. In: VAN ZANTEN, A. (Dir.). Dictionnaire de l'éducation. Paris: Quadrige/PUF, sept. 2008.

MORUCHOWICZ, A. Carreiras, incentivos e estruturas salariais docentes. Documentos Preal, Washington, DC, n. 23, jun. 2003. Disponível em:<www.preal.org/biblioteca>. Acesso em: 13 fev. 2012.

OLIVEIRA, D.A. A política educativa, a crise da escola e a promoção da justiça social. In: FERREIRA, E.B.; OLIVEIRA, D.A. (Org.).Crise da escola e políticas educativas. Belo Horizonte: Autentica, 2009.

OYADOMARY, J.C.T; COELHO, C. Remuneração variável e congruência de metas. 2009. Disponível em: <www.anpcont.com.br>. Acesso em: 13 fev. 2012.

RANSON, S. Public accountability in the age of neo-liberal governance. Jornal of Education Policy, v. 18, n. 5, p. 454-458. 2003.

SOUSA, S.Z.L. Avaliação do rendimento escolar como instrumento de gestão educacional. In: OLIVEIRA, D.A. Gestão democrática da educação. Desafios contemporâneos. Petrópolis: Vozes, 2003.

SOUSA, S.Z.L.; LOPES, V.V. Avaliação nas políticas educacionais atuais reitera desigualdades. Revista Adusp, São Paulo, v. 1, p. 54-59, jan. 2010.

VILHENA, R. et al. (Org.). O choque de gestão em Minas Gerais: políticas da gestão pública para o desenvolvimento. Belo Horizonte. Editora da UFMG, 2006.

WOLD BANK. Documents Achieving World-Class Education in Brazil: the next agend. Nov. 2011. Disponível em: <www.worldbank.publications.doc.>. Acesso em: 25 mar. 2012.

Recebido em 18 de agosto de 2013.

Aprovado em 19 de novembro de 2013. 
